\title{
Extracellular signal-Regulated Kinases1/2 and their role in cardiac diseases
}

\author{
Maria Chatzifrangkeskou ${ }^{1,2,3,4}$, Antoine Muchir ${ }^{1,2,3,4}$ \\ ${ }^{1}$ Sorbonne Universités, UPMC Univ Paris 06, Center of Research in Myology, UMRS 974, F-75013, Paris, France \\ ${ }^{2}$ INSERM U974, F-75013, Paris, France \\ ${ }^{3}$ CNRS FRE 3617, F-75013, Paris, France \\ ${ }^{4}$ Institut de Myologie, F-75013, Paris, France \\ Correspondence: Antoine Muchir \\ E-mail: a.muchir@institut-myologie.org \\ Received: November 29, 2014 \\ Published online: January 28, 2015
}

\begin{abstract}
Mitogen-activated protein (MAP) kinases are members of a well-studied family of serine/threonine protein kinases involved in signal transduction pathways, which control multiple cellular processes. The extracellular signal-regulated kinase (ERK1/2) cascade is a MAP kinase pathway that transmits signals from the cell surface to substrates either in the nucleus or in the cytoplasm. The transmission of the signal through the ERK1/2 cascade is mediated by serial phosphorylations and activations of protein kinases. Abnormal regulation of the ERK1/2 signals has been linked to diseases and recent work clearly implicated ERK1/2 signaling in the development of cardiac pathologies. Understanding the underlying mechanism and the consequences of the aberrant modulation of ERK1/2 cascade will lead to the development of pharmacologic inhibitors for the treatment of these cardiac disorders.
\end{abstract}

Keywords: Mitogen-activated protein (MAP) kinases; Lamin; cardiomyopathy; Extracellular signal-regulated kinases $1 / 2$

To cite this article: Maria Chatzifrangkeskou, et al. Extracellular signal-RegulatedKinases1/2 and their role in cardiac diseases. Sci Proc 2015; 2: e457. doi: 10.14800/nt.457.

\section{Introduction}

A proportion of inherited cardiomyopathies display deregulated MAP kinase signaling. As these diseases are a major cause of cardiac disease in human, it is therefore not surprising that the MAP kinase signaling continues to be the subject of intense researches for future pharmacological intervention. The development of molecules targeting this pathway has focused mostly on the development of small-molecule inhibitors. This review will gather information on MAP kinase signaling, focusing on the ERK1/2 branch and will discuss important research progresses in the field of inherited cardiomyopathies. The recent years provided some clues to explain the pathogenesis of such disease, involving ERK1/2, which might open novel and promising perspectives for future clinical trials.

\section{MAP kinases}

Protein kinases are important players to achieve the integrated function of cells. Protein kinases are able to transfer phosphoryl groups onto target proteins, altering their activity ${ }^{[1]}$. This mechanism participates in the transmission of intra- and extracellular signals throughout the cell and to the nucleus. Thus, protein kinases play a pivotal role in signaling pathways that could regulate cell growth, differentiation, development, and death ${ }^{[2]}$. Hence, any disruption of the phosphorylation could alter cell functions and may cause diseases ${ }^{[3]}$. 
The kinases are classified by the amino acids they phosphorylate ${ }^{[4]}$. The two main classes of kinases are tyrosine kinases, which phosphorylate tyrosine, and serine-threonine kinases, which phosphorylate serine or threonine ${ }^{[5]}$. Manning et al. have defined the human «kinome space » consisting of more than 500 protein kinase genes ${ }^{[6]}$. A growing number of diseases are caused by deregulation of the phosphorylation, and thus protein kinases are regarded as a promising therapeutic target for diseases.

There is a family of protein kinase cascades known as mitogen-activated protein (MAP) kinases ${ }^{[7,8]}$, which belongs to serine-threonine kinases. It comprises MAP kinases, MAP kinase kinases (MKKs) and MAP kinase kinase kinases (MKKKs) ${ }^{[9]}$. MKKKs phosphorylate and activate MKKs, which in turn phosphorylate and activate MAP kinases. In all currently known MAP kinase cascades, the kinase immediately upstream of the MAP kinase is a member of the MAP/ERK kinase (MEK) family ${ }^{[10-13]}$, which are dual specificity enzymes that can phosphorylate serine/threonine and tyrosine residues. In spite of their ability to phosphorylate MAP kinases proteins, the substrate specificity of the known MEKs is very narrow: each MEK phosphorylates only one or a few of the MAP kinases. Much of the review highlights knowledge on extracellular signal-regulated kinases 1 and 2 (ERK1 and ERK2), two of the known MAP kinases.

\section{ERK1/2}

ERK1 and ERK2 are ubiquitously expressed proteins of 44 and $42 \mathrm{kDa}$, which are nearly $85 \%$ identical in their amino-acid sequences ${ }^{[14-17]}$. Stimulation of different receptors can activate ERK1/2, e.g. receptors with intrinsic tyrosine kinase activity, cytokine receptors and G-protein-coupled receptors. Hence, ERK1/2 are stimulated by many extracellular ligands and cellular perturbations (e.g., mechanical stress, osmotic shock), with some cell type specificity ${ }^{[7]}$. ERK1 and ERK2 are activated by closely related MEKs, MEK1 and MEK2 ${ }^{[10,18-21]}$. It has been assumed, from lack of evidence to the contrary, that MEK1/2 have no other substrates. This specificity of MEK1/2 has been used by several pharmacological companies to design potent inhibitors of ERK1/2 signaling ${ }^{\text {[22] }}$. A vast majority of the known MEK1/2 inhibitors are ATP non-competitive (i.e., they do not directly compete for the ATP binding site). These MEK1/2 inhibitors bind to a unique allosteric site adjacent to the ATP site, which explains their high specificity.

Of all the known MEKKs, Raf isoforms are the only ones known to date, which phosphorylate MEK1 and MEK2 ${ }^{[23-27]}$. Stimulation of extracellular receptors by ligands results in the activation of the protein Ras, which can interact with several effectors, including Raf isoforms. ERK1/2 signaling requires the spatial and temporal organization of three different kinases, Raf, MEK1/2 and ERK1/2. This is controlled by scaffold molecules ${ }^{[28]}$, among which some have been identified in cardiac tissue (e.g., $\beta$-arrestin, FHL1, paxillin) ${ }^{[29]}$. These scaffold molecules have important functions: i/ they organize ERK1/2 for the efficient activation in the cascade; and ii/ they determine the output signal by localizing ERK1/2 to selected sites of action, (e.g., the transcription machinery, the actin cytoskeleton). Phosphorylation by ERK1/2 induces conformational change of the substrate, which thereby, either induces their activation, or regulates their association with other molecules ${ }^{\text {[30] }}$. To date, more than 150 substrates of ERK1/2 have been reported ${ }^{[31]}$, which can be categorized into several categories including: i/ transcription factors, ii/ protein kinases and phosphatases, iii/ cytoskeletal proteins, iv/ receptors, and vi/ others. ERK1/2 can translocate to the nucleus where they are able to phosphorylate transcription factors to regulate their activities (e.g., c-Jun, c-Fos and ATF-2, Elk-1). Although many ERK1/2's substrates are localized in the nucleus and are phosphorylated after ERKs' nuclear translocation, the number of cytosolic ERK substrates is not much smaller. It has been described that several cytoskeletal element are targets for ERK1/2 (e.g., tubulin ${ }^{[32]}$, vimentin ${ }^{\text {[3] }}$ or cortactin $\left.{ }^{[34]}\right)$.

\section{ERK1/2 and inherited cardiomyopathies}

Studies point to ERK1/2 as a maladaptive signaling pathway in cardiomyopathy. Cardiomyopathy is an anatomic and pathologic condition associated with muscle and electrical dysfunction of the heart, which may be confined to the heart or may be part of a generalized systemic disorder, often leading to heart failure-related disability. A well-known negative effect of ERK1/2 signaling in human heart function is highlighted by the fact that different mutations able to increase ERK1/2 pathway activation lead to cardiac pathologies in patients with Noonan and related syndromes, such as Costello, LEOPARD and cardio-facio-cutaneous syndromes [35-38]. Knock-in mice expressing a Noonan syndrome-associated mutation exhibit enhanced ERK1/2 signaling and an accelerated transition toward heart failure in response to pressure overload. Interestingly, postnatal treatment with MEK1/2 inhibition normalizes cardiac defects ${ }^{[39]}$. Based on these results, Novartis recently launched a clinical trial on Noonan syndrome using a MEK1/2 inhibitor (ClinicalTrials.gov Identifier: NCT01556568).

A further example is represented by mutations in the A-type lamin gene and causing dilated cardiomyopathy. Since 1999, scientists have unraveled the role of the nuclear lamina in the development of cardiac disease ${ }^{[40]}$. LMNA encodes 
nuclear A-type lamins via alternative splicing ${ }^{[41]}$. Lamins are intermediate filament proteins that polymerize to form the nuclear lamina, a fibrous meshwork underlining the inner nuclear membrane of most eukaryotic cells. We recently demonstrated an aberrant increase in ERK1/2 activity in hearts from a mouse model of the disease ${ }^{[42]}$. These results provide proof of principle for ERK1/2 inhibition as a therapeutic option to prevent or delay the onset of heart failure in LMNA cardiomyopathy. Pharmacological or genetic blockade of signaling in the ERK1/2 cascade in these mice improves left ventricular dilatation and deterioration in cardiac contractility ${ }^{[43-46]}$.

\section{Conclusion}

Less than a decade ago the kinases constituting MAP kinase pathways were identified through intense efforts to understand the molecular events underlying cellular responses to extracellular signals. The kinases constituting ERK1/2 pathways appear to be key cellular signal transducers and thus attractive targets for drug development. These efforts are now beginning to bear fruit with the initiation of clinical trials in human cardiac diseases. Their positive outcome would be a triumph of translating basic scientific understanding of cellular function into successful human therapies.

\section{Conflict of Interest}

Dr. Muchir is inventor on a pending United States patent application on methods for treating and/or preventing cardiomyopathies by ERK inhibition filed by the Trustees of Columbia University in the City of New York.

\section{References}

1. Blagden S, de Bono J. Drugging cell cycle kinases in cancer therapy. Curr Drug Targets 2005; 6:325-335.

2. Cheetham GM. Novel protein kinases and molecular mechanisms of autoinhibition. CurrOpinStructBiol 2004; 14:700-705.

3. Cohen P. Protein kinases - the major drug targets of the twenty-first century? Nat Rev Drug Discov2002 ; 1:309-315.

4. Shchemelini I, Sefc L, Necas E. Protein kinases, their function and implication in cancer and other diseases. Folia Biologica 2006; 52:81-101.

5. Knighton DR, Zheng JH, Ten Eyck LF, Ashford VA, Xuong NH, Taylor SS, et al. Crystal structure of the catalytic subunit of cyclic adenosine monophosphate-dependent protein kinase. Science 1991; 253:407-414.

6. Manning G, Whyte DB, Martinez R, Hunter T, Sudarsanam S. The protein kinase complement of the human genome. Science 2002; 298:1912-1934.

7. Lewis TS, Shapiro PS, Ahn NG. Signal transduction through MAP kinase cascades. Adv Cancer Res 1998; 74:49-139.
8. Errede B, Cade RM, Yashar BM, Kamada Y, Levin DE, Irie K, et al. Dynamics and organization of MAP kinase signal pathways. Mol Reprod Dev 1995; 42:477-485.

9. Johnson GL, Dohlman HG, Graves LM. MAPK kinase kinases (MKKKs) as a target class for small-molecule inhibition to modulate signaling networks and gene expression. Curr Opin Chem Biol 2005; 9:325-331.

10. Crews C, Alessandrini A, Erikson R. The primary structure of MEK, a protein kinase that phosphorylates the ERK gene product. Science 1992; 258:478-480.

11. Kosako H, Gotoh Y, Matsuda S, Ishikawa M, Nishida E. Xenopus MAP kinase activator is a serine/threonine/tyrosine kinase activated by threonine phosphorylation. EMBO J 1992; 11:29032908.

12. Wu J, Harrison JK, Vincent LA, Haystead C, Haystead TAJ, Michel $\mathrm{H}$, et al. Molecular structure of a protein-tyrosine/threonine kinase activating p42 mitogen activated protein (MAP) kinase: MAP kinase kinase. Proc Natl Acad Sci USA 1993; 90:173-177.

13. Ashworth A, Nakielny S, Cohen P, Marshall C. The amino acid sequence of a mammalian MAP kinase kinase. Oncogene 1992; 7:2555-2556.

14. Boulton TG, Yancopoulos GD, Gregory JS, Slaughter C, Moomaw C, Hsu J, et al. An insulin-stimulated protein kinase similar to yeast kinases involved in cell cycle control. Science 1990; 249:64-67.

15. Boulton TG, Nye SH, Robbins DJ, Ip NY, Radziejewska E, Morgenbesser SD, et al. ERKs: a family of protein-serine/threonine kinases that are activated and tyrosine phosphorylated in response to insulin and NGF. Cell 1991; 65:663-675.

16. Payne DM, Rossomando AJ, Martino P, Erickson AK, Her JH, Shananowitz J, et al. Identification of the regulatory phosphorylation sites in pp42/mitogen activated protein kinase (MAP kinase). EMBO J 1991; 10:885-892.

17. Ferrell JE, Bhatt RR. Mechanistic studies of the dual phosphorylation of mitogen-activated protein kinase. J Biol Chem 1997; 272:19008-19016.

18. Ahn NG, Seger R, Bratlien RL, Diltz CD, Tonks NK, Krebs EG. Multiple components in an epidermal growth factor-stimulated protein kinase cascade. In vitro activation of a myelin basic protein/microtubule-associated protein 2 kinase. J Biol Chem 1991; 266: 4220-4227.

19. Seger R, Ahn NG, Posada J, Munar ES, Jensen AM, Cooper JA, et al. Purification and characterization of mitogen-activated protein kinase activator(s) from epidermal growth factor-stimulated A431 cells. J Biol Chem 1992; 267:14373-14381.

20. Zheng CF, Guan K. Dephosphorylation and inactivation of the mitogen-activated protein kinase by a mitogen-induced Thr/ Tyr protein phosphatase. J Biol Chem 1993; 268:16116-16119.

21. Nakielny S, Cohen P, Wu J, Sturgill T. MAP kinase activator from insulin-stimulated skeletal muscle is a protein threonine/ tyrosine kinase. EMBO J 1992; 11:2123-2130.

22. Akinleye A, Furqan M, Mukhi N, Ravella P, Liu D. MEK and the inhibitors : from bench to bedside. J Hemat Oncol 2013; 6: 27-38.

23. Kyriakis JM, App H, Zhang XF, Banerjee P, Brautigan DL, Rapp 
http://www.smartscitech.com/index.php/sp

UR, et al. Raf-1 activates MAP kinase-kinase. Nature 1992; 358:417-421.

24. Dent P, Haser W, Haystead TAJ, Vincent LA, Roberts TM, Sturgill TW. Activation of mitogen-activated protein kinase kinase by v-Raf in NIH 3 T3 cells and in vitro. Science 1992; 257:14041407.

25. Force T, Bonventre JV, Heidecker G, Rapp U, Avruch J, Kyriakis JM. Enzymatic characteristics of the c-Raf-1 protein kinase. Proc Natl Acad Sci USA 1994; 91:1270-1274.

26. Pawson T, Scott JD. Signaling through scaffold, anchoring, and adaptor proteins. Science 1997; 278:2075-2080.

27. Hunter T. Protein kinases and phosphatases: the yin and yang of protein phosphorylation and signaling. Cell 1995; 80:225-236.

28. Pearson G, Robinson F, Beers Gibson T, Xu BE, Karandikar M, Berman $\mathrm{K}$, et al. Mitogen-activated protein (MAP) kinase pathways: regulation and physiological function. Endocrine Reviews 2001; 22:153-183.

29. Tarone G, Sbroggio M, Brancaccio M. Key role of ERK1/2 molecular scaffolds in heart pathology. Cell Mol Life Sci 2013; 70:4047-4054.

30. Chuderland D, Seger R. Protein-protein interactions in the regulation of the extracellular signal-regulated kinase. Mol Biotechnol 2005; 29:57-74.

31. Yoon S, Seger R. The extracellular signal-regulated kinase: multiple substrates regulate diverse cellular function. Growth factors 2006; 24:21-44.

32. Reszka AA, Seger R, Diltz CD, Krebs EG, Fischer EH. Association of mitogen-activated protein kinase with the microtubule cytoskeleton. Proc Natl Acad Sci USA 1995; 92:8881-8885.

33. Perlson E, Hanz S, Ben-Yaakov K, Segal-Ruder Y, Seger R, Fainzilber M. Vimentin-dependent spatial translocation of an activated MAP kinase in injured nerve. Neuron 2005; 45:715-726.

34. Martinez-Quiles N, Ho HY, Kirschner MW, Ramesh N, Geha RS. Erk/Src phosphorylation of cortactin acts as a switch on switch off mechanism that controls its ability to activate NWASP. Mol Cell Biol 2004; 24:5269-5280.

35. Bueno OF, De Windt LJ, Tymitz KM, Witt SA, Kimball TR, Klevitsky $\mathrm{R}$, et al. The MEK1-ERK1/2 signaling pathway promotes compensated cardiac hypertrophy in transgenic mice. EMBO J 2000; 19:6341-6350.

36. Purcell NH, Wilkins BJ, York A, Saba-El-Leil MK, Meloche S, Robbins J, et al. Genetic inhibition of cardiac ERK1/2 promotes stress-induced apoptosis and heart failure but has no effect on hypertrophy in vivo. Proc Natl Acad Sci USA 2007; 104:1407414079.

37. Pandit B, Sarkozy A, Pennacchio LA, Carta C, Oishi K, Martinelli $\mathrm{S}$, et al. Gain-of-function RAF1 mutations cause Noonan and LEOPARD syndromes with hypertrophic cardiomyopathy. Nat Genet 2007; 39:1007-1012.

38. Nakamura T, Colbert M, Krenz M, Molkentin JD, Hahn HS, Dorn $\mathrm{GW}$, et al. Mediating ERK 1/2 signaling rescues congenital heart defects in a mouse model of Noonan syndrome. J Clin Invest 2007; 117:2123-2132.

39. Wu X, Simpson J, Hong JH, Kim KH, Thavarajah NK, Backx PH, et al. MEK-ERK pathway modulation ameliorates disease phenotypes in a mouse model of Noonan syndrome associated with the Raf1 (L613V) mutation. J Clin Invest 2011; 121:10091025.

40. Bonne G, Di Barletta MR, Varnous S, Becane HM, Hammouda $\mathrm{EH}$, Merlini L, et al. Mutations in the gene encoding lamin $\mathrm{A} / \mathrm{C}$ cause autosomal dominant Emery-Dreifuss muscular dystrophy. Nat Genet 1999; 21:285-288.

41. Lin F, Worman HJ. Structural organization of the human gene encoding nuclear lamin A and nuclear lamin C. J Biol Chem 1993; 268:16321-16326.

42. Muchir A, Pavlidis P, Decostre V, Herron AJ, Arimura T, Bonne G, et al. Activation of MAPK Pathway Links LMNA Mutations to Cardiomyopathy in Emery-Dreifuss Muscular Dystrophy. J Clin Invest 2007; 117:1282-1293.

43. Muchir A, Shan J, Bonne G, Lehnart SE, Worman HJ. Inhibition of extracellular signal-regulated kinase signaling to prevent cardiomyopathy caused by mutation in the gene encoding A-type lamins. Hum Mol Genet 2009;18:241-247.

44. Wu W, Muchir A, Shan J, Bonne G, Worman HJ. Mitogen-activated protein kinase inhibitors improve heart function and prevent fibrosis in cardiomyopathy caused by mutation in lamin A/C gene. Circulation 2011; 123:53-61.

45. Muchir A, Reilly SA, Wu W, Iwata S, Homma S, Bonne G, et al. Treatment with selumetinib preserves cardiac function and improves survival in cardiomyopathy caused by mutation in the lamin A/C gene. Cardiovasc Res 2012; 93:311-319.

46. Wu W, Iwata S, Homma S, Worman HJ, Muchir A. Depletion of extracellular signal-regulated kinase 1 in mice with cardiomyopathy caused by lamin $\mathrm{A} / \mathrm{C}$ gene mutation partially prevents pathology before isoenzyme activation. Hum Mol Genet 2014; 23:1-11. 